\title{
IDENTIFICAÇÃO DE ÁREAS ALTERNATIVAS PARA DISPOSIÇÃO DE RESÍDUOS SÓlIDOS NA REGIÃO dO BAIXO RIBEIRA DO IGUAPE - SP
}

\section{IDENTIFICATION OF ALTERNATIVE AREAS FOR SOLID WASTE DISPOSAL IN BAIXO RIBEIRA DO IGUAPE - SP}

\author{
MARIA LÚCIA CALIJURI \\ Engenheira Civil - D.Sc. Engenharia Civil pela EESC/USP. Professora Titular do Departamento de Engenharia Civil da UFV \\ Samuel Santana Paes Loures \\ Engenheiro Civil - Doutorando em Engenharia Civil - UFV \\ ANíbAL DA FONSECA SANTIAGO \\ Engenheiro Ambiental - Mestrando em Engenharia Hidráulica e Saneamento - EESC/USP

\section{CARlos ERnesto G. R. SCHAEFER}

Engenheiro Agrônomo - P.PhD pela University of Western Austrália. Professor Adjunto do Departamento de Solos - UFV

WILSON GANDINI LUGÃO

Engenheiro Agrimensor - Doutorando em Engenharia Civil - UFV

José ERNESTo MATTOS ALVES

Graduando em Agronomia - UFV

Código ABES: 129/06 Recebido: 25/09/06 Aceito: 17/07/07

\section{RESUMO}

Este trabalho teve por objetivo a proposição de cenários para o equacionamento da disposição de resíduos sólidos gerados por áreas urbanas da regiáo do Baixo Ribeira de Iguape, localizado no estado de São Paulo. Utilizou-se a análise multicritério, que requer a identificação de critérios que podem ser restriçôes e fatores. Como critérios de agregação optou-se pela Combinação Linear Ponderada e pela Média Ponderada Ordenada. Para cada um dos municípios calculou-se a área necessária para a disposição final de seus resíduos sólidos. Os resultados mostraram que a melhor área para o município de Cajati está localizada a aproximadamente $3,0 \mathrm{~km}$ da sede do mesmo, para Jacupiranga a 2,7km e para Pariqüera-Açu a $2,4 \mathrm{~km}$. A metodologia mostrou-se adequada ao propósito em questão, levando-se em consideração 18 fatores e restrições influentes no processo de decisão.

PALAVRAS-CHAVE: Resíduos sólidos, disposição de resíduos sólidos, análise multicritério, aterro sanitário, seleção de áreas

\section{ABSTRACT}

This paper addresses the proposition of scenarios for the equation of the disposal of solid residues generated by urban areas of the region of the Baixo Ribeira de Iguape, located in the São Paulo State, Brazil. Multicriterion analysis requiring identification of criteria that can play restrictions and factors roles were used. Aggregation Criteria was represented by the Weighed Linear Combination and the Ordered Weighed Mean. For each one of the selected cities it was calculated the required area for the final disposal of its solid residues. The results had shown that the best area for the city of Cajati is located approximately 3,0 km of its headquarters, for Jacupiranga 2,7 km and for Pariqüera-Açu $2,4 \mathrm{~km}$. The applied methodology revealed adequate to the objective of this research, taking into account 18 influential factors and restrictions in the decision process.

KEYWORDS: Solids waste, solids waste disposal, multicriteria analysis, sanitary landfill, site selection

\section{INTRODUÇÃO}

O homem, no desenvolvimento de suas atividades diárias (sociais, residenciais, comerciais e industriais, dentre outras), gera e descarta uma grande quantidade de resíduos. Mesmo diminuindo e controlando a produção de lixo ele sempre irá produzi-lo (Pereira Neto, 1999). Portanto a necessidade de se fazer manejo e gerenciamento adequado dos resíduos sólidos é um grande e persistente desafio. Nesse contexto, os aterros sanitários constituem-se em peças de fundamental importância. Segundo Tsuhako (2004), a disponibilidade de áreas para a disposição de resíduos é cada vez mais escassa, à 
medida que cresce a urbanização e a taxa de geração de resíduos sólidos, requerendo a seleção de locais cada vez mais precisa e criteriosa.

A disposição final do lixo em áreas impróprias e executadas sem estudo detalhado do local provoca sérios problemas ambientais e sociais. O local ideal à implantação de um aterro sanitário deve reunir condições técnicas, econômicas e ambientais com vistas a evitar ou minimizar impactos (Tsuhako, 2004).

Os sistemas de informação geográfica são, há muito tempo, utilizados como ferramentas de apoio à decisão, por manipular grandes volumes de dados, integrar imagens orbitais, e possuir potencial para realizar grande diversidade de análises com eficiência (baixo custo e curto espaço de tempo).

Este trabalho está inserido em um contexto maior que é o "Estudo dos sistemas naturais e artificiais redutores de cargas poluidoras para a sustentabilidade dos recursos hídricos do Baixo Ribeira de Iguape-SP" e teve por objetivo a proposição de cenários para o equacionamento da disposição de resíduos sólidos gerados por áreas urbanas dessa região.

\section{ÇARACTERIZAÇÃO DA AREA}

A área de estudo compreende as bacias hidrográficas dos rios Jacupiranga e Pariqüiera-Açu e situa-se entre as coordenadas $24^{\circ} 30^{\prime}$ e $25^{\circ} 0$ ' de latitude Sul e $48^{\circ} 20^{\prime}$ e $47^{\circ} 43^{\prime}$ de longitude W, no Estado de São Paulo, como apresentado na Figura 1.

Estão inseridos nessa área os municípios de Cajati, Jacupiranga e Pariqüera-Açu. O município de Registro não incluído no estudo, embora se localize fora desses limites, é reconhecido como integrante da unidade administrativa conhecida por Baixo Ribeira.

O processo de ocupação dessa região se deu a partir dos anos de 1960 , principalmente após a construção da rodovia Régis Bittencourt (BR-116), que atravessa todos os municípios do Baixo Ribeira, e faz a conexão entre as capitais São Paulo e Curitiba.

Essa região caracteriza-se por ser a mais pobre, a menos urbanizada, com menor densidade demográfica e menos desenvolvida do estado de São Paulo. Apresenta os piores indicadores sócio-econômicos do estado, com baixos níveis de renda e escolaridade, altos índices de mortalidade infantil e analfabetismo, e condições precárias de infra-estrutura e saneamento básico. Os municípios possuem baixa arrecadação e mínima capacidade de investimento público, sendo que a maioria apresenta índices de desenvolvimento humano (IDH) bastante baixos no contexto estadual (ISA, 1998).

O clima regional é caracterizado como subtropical úmido, com temperatura média anual de $18^{\circ} \mathrm{C}$ e precipitação anual podendo atingir até $4.000 \mathrm{~mm}$. $\mathrm{O}$ relevo é fortemente ondulado, com altitude variando entre 100 a 1000 metros o que caracteriza áreas de difícil acesso.

A Figura 2 apresenta a hidrografia e o sistema viário da área de estudo.

Quanto à geologia, essa região caracteriza-se por um conjunto de rochas supracrustais vulcano-sedimentares, de grau metamórfico fraco a médio, cujo embasamento é formado por rochas gnássico-migmatíticas, localmente charnockíticas e com intercalaçōes metassedimentares com grau metamórfico médio a alto.
Segundo (Karmann, 1994), a estrutura regional é constituída por uma série de intrusões granitóides que afetam tanto a seqüência supracrustal, como também o embasamento. Estas intrusões e rochas associadas possivelmente contribuíram como principal fonte de origem da matéria prima lítica na região. Ressalta-se um sistema anastomosado de zonas de cisalhamento transcorrentes, verticalizadas a subhorizontais, de caráter dúctil a dúctil-rúptil, de movimentação na direção NE-SW, e rejeitos quilométricos. Este sistema de cisalhamento imprime uma compartimentação da região em blocos tectônicos, cujas formas são lenticularizadas, com alongamentos maiores na direção genérica NE-SW.

As classes de solos predominantes na regiāo são os Argissolos e Cambissolos Háplicos. Ocorrem também Latossolo Vermelho-Amarelo, Gleissolos Háplicos, Neossolos Litólicos e uma pequena mancha de Chernossolo. A metodologia para o mapeamento dos solos será descrita posteriormente.

\section{METODOLOGIA}

Esse trabalho fez uso da base de dados (altimetria, hidrografia e sistema viário) do Instituto Brasileiro de Geografia e Estatística (IBGE), escala 1:50.000; mapa geológico, escala 1:500.000, do Instituto de Pesquisas Tecnológicas do Estado de São Paulo; imagem orbital, órbita-ponto 220/77 - Sensor a bordo do satélite LandSat 7, data 13-03-2003. Características da imagem LandSat 7: resolução espectral 8 bits, resolução espacial $30 \mathrm{~m}$ ou $15 \mathrm{~m}$ (MS fusão banda PAN), faixa de varrimento $185 \mathrm{~km}$; mapa de solos, escala 1:100.000, desenvolvido no âmbito desse projeto.

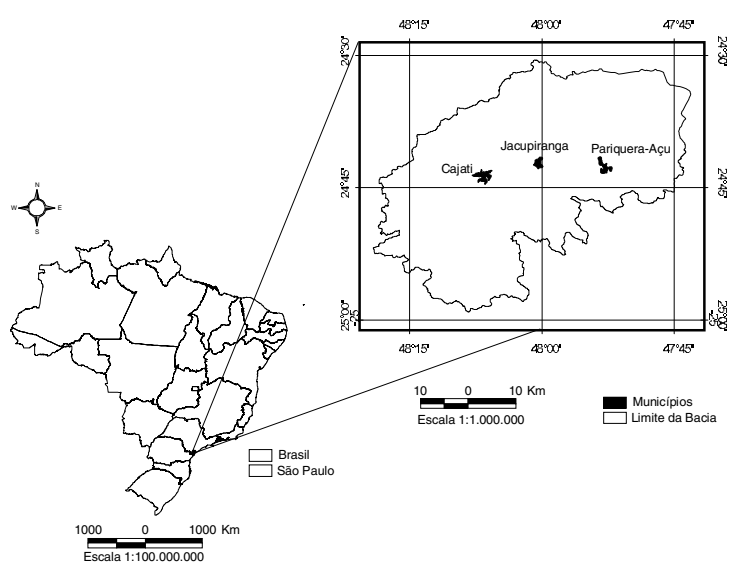

Figura I - Localização da área de estudo

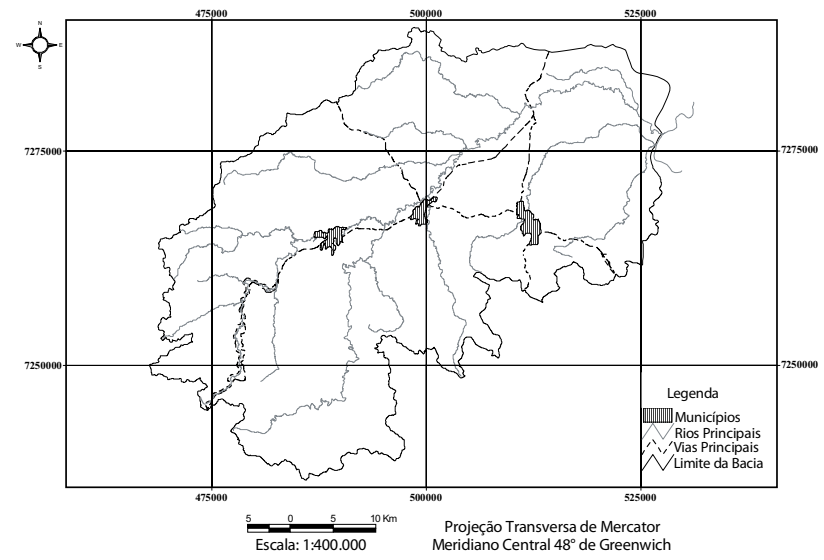

Figura 2 - Hidrografia e sistema viário 
As principais unidades geoambientais foram delimitadas com base no modelo digital de elevação hidrologicamente consistente, no mapa de solos, escala 1:500.000 (Instituto Agronômico de Campinas, 1999), e no mapa geológico, escala 1:500.000 (SICCT, 1981). Realizou-se trabalho de campo para verificar e corrigir os limites das unidades fisiográficas. Coletaram-se e analisaram-se em laboratório físico/químico amostras referentes aos pontos representativos para descrever as características das unidades taxonômicas.

O mapa de cobertura vegetal foi obtido por meio do tratamento das imagens provenientes do sensor de mapeamento temático realçado da plataforma orbital LandSat 7, de onde extraíram-se informaçôes para o reconhecimento de padrōes e objetos homogêneos. Os mapas do sistema viário e da hidrografia foram utilizados como referências para o georreferenciamento da imagem.

A interpretação visual e a extração das amostras de treinamento foram feitas a partir da composição colorida, obtida da combinação das bandas 3, 4 e 5 nos canais do vermelho, verde e azul, respectivamente. Estas três bandas foram selecionadas para o processamento das imagens por distinguirem melhor as classes de uso da terra. As amostras de treinamento, retiradas pela interpretação visual da imagem, foram validadas em trabalhos de campo.

Adotou-se o método de classificação supervisionada com uso do algoritmo da Máxima Verossimilhança. Optou-se por retirar da imagem produzida algumas classes encontradas devido a alta probabilidade de confusão durante a análise, irrelevância, e mesmo, posse de dados cartográficos mais detalhados que os encontrados na classificação da imagem. As informações referentes à hidrografia foram suprimidas por dois motivos distintos: a imagem não apresentou resolução espacial suficiente para identificar e categorizar os cursos d'água secundários e, os cursos d'água principais exibiram resposta espectral idêntica ao de vias não pavimentadas, devido ao fato de ter havido precipitação e conseqüente carreamento de partículas de solos para a água, provocando a confusão entre estas duas classes. Os dados referentes ao sistema viário, ao polígono limitante das cidades e a hidrografia foram utilizados da base de dados do IBGE, na escala 1:50.000. As áreas de cobertura de nuvens e suas respectivas sombras também foram suprimidas por não apresentarem relevância para a análise. A carta de uso do solo obtida apresentou 7 classes, sendo $45,2 \%$ da área coberto por Formaçôes Florestais, $27,4 \%$ coberto por agricultura, $12,82 \%$ campos, $9,3 \%$ pastagens, $1,94 \%$ recursos hídricos, $1,36 \%$ área urbana, e $0,03 \%$ solo exposto.

Como ferramentas utilizou-se o IDRISI 15, The Andes Edition, Clark Labs, Clark University 2006 e ESRI®ArcMap ${ }^{\mathrm{TM}}$ 9.0, 2004.

Com vistas a incluir na análise a fragilidade ambiental da relação declividade-solos-morfologia-uso do solo e cobertura vegetal, elaborou-se uma carta síntese que permitiu avaliar de forma integrada as potencialidades e vulnerabilidades do meio ambiente.

A carta de fragilidade foi produzida agregando-se pela combinação linear ponderada as cartas de declividade, solos, morfologia, uso do solo e cobertura vegetal. Cada um desses fatores foi subdividido em classes que receberam valores de um a cinco. Quanto menor o valor maior o grau de proteção, menor a susceptibilidade ou vulnerabilidade.

A carta de declividade foi dividida em: muito baixa, $<5 \%$; baixa, 6 a $12 \%$; média, 12 a $20 \%$; alta, 20 a $30 \%$ e muito alta, > 30\%.

Os solos foram valorados quanto a susceptibilidade à erosão em: muito baixa, Latossolo Vermelho Amarelo (LVAd2); baixa, Gleissolo (GXbd2), Latossolo Vermelho Amarelo (LVAd1), Chernossolo (MT); média, Gleissolo (GXbd1), Argissolo (PVAd); alta, Cambissolo (CXbd2), e muito alta, Neossolo (RLd), Cambissolo (CXbd1).

A morfologia foi classificada, quanto a susceptibilidade à erosão, em média, forma convexa e muito alta, forma côncava. O uso do solo e a cobertura vegetal foram classificados em muito baixa, formaçōes florestais; baixa, campos; média, pastagem; alta, áreas urbanas; e em muito alta, agricultura e solo exposto.

Esses fatores foram comparados dois a dois e valorados. Os pesos obtidos na matriz de comparação foram 0,3077 para a declividade, 0,2819 para os solos, 0,2600 para uso do solo e cobertura vegetal e 0,1505 para a morfologia.

Foram estabelecidas cinco classes de fragilidade variando de muito baixa a muito alta. A carta de fragilidade obtida com essa metodologia mostrou-se coerente com os geoambientes identificados em trabalhos de campo, e está mostrada na Figura 3.

As análises espaciais foram realizadas utilizando-se o módulo de apoio à decisão, com critérios múltiplos para selecionar as áreas mais adequadas à disposição de resíduos sólidos.

A avaliação por critérios múltiplos foi utilizada para avaliar e agregar os critérios oriundos de informaçôes existentes ou geradas. Como critérios foram utilizados fatores e restrições. Os fatores são limitações relativas que definem algum grau de aptidão para as regiōes geográficas, enquanto as restriçôes possibilitam a imposição de limitaçôes absolutas a determinados espaços geográficos.

Os valores de adequabilidade foram padronizados em uma escala contínua, variando de zero a 255, de duas formas: utilizando a lógica fuzzy através de suas funçōes ou definidos pelo usuário (dados categóricos). A Tabela 1 apresenta, de forma sintética, os critérios estabelecidos para a análise.

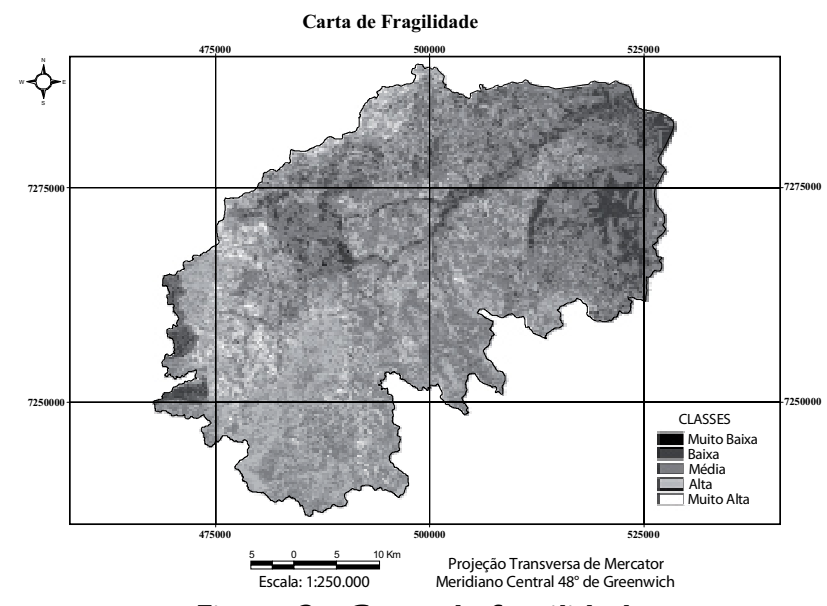

Figura 3 - Carta de fragilidade 
Tabela I - Critérios da análise

\begin{tabular}{|c|c|c|c|c|c|c|}
\hline \multirow[t]{3}{*}{ Tema } & \multirow[t]{3}{*}{ Restrição } & \multicolumn{5}{|c|}{ Fator } \\
\hline & & \multirow{2}{*}{ Função } & \multicolumn{4}{|c|}{ PC } \\
\hline & & & a (metros) & $\mathrm{b}(\mathrm{m})$ & $\mathrm{c}(\mathrm{m})$ & $\mathrm{d}(\mathrm{m})$ \\
\hline Hidrografia & & & & & & \\
\hline $\begin{array}{c}1 \text { Rio Ribeira de Iguape e } \\
\text { afluentes principais }\end{array}$ & $\begin{array}{l}1 \text { distância mínima de } \\
50 \text { metros (buffer) }\end{array}$ & Linear crescente & zero & 300 & 300 & 300 \\
\hline \multicolumn{7}{|l|}{2 afluentes secundários } \\
\hline & $\begin{array}{l}2 \text { distância mínima de } \\
30 \text { metros (buffer) }\end{array}$ & Linear crescente & zero & 200 & 200 & 200 \\
\hline Áreas Urbanizadas & $\begin{array}{l}\text { Distância mínima de } \\
3000 \text { metros (buffer) }\end{array}$ & $\begin{array}{c}\text { Linear } \\
\text { decrescente }\end{array}$ & 3000 & 3000 & 3000 & 33400 \\
\hline \multicolumn{7}{|l|}{ Sistema Viário } \\
\hline $\begin{array}{c}1 \text { rodovias federais e estaduais } \\
\text { pavimentadas }\end{array}$ & $\begin{array}{l}1 \text { Distância mínima de } \\
100 \text { metros (buffer) }\end{array}$ & $\begin{array}{c}\text { Linear } \\
\text { decrescente }\end{array}$ & 100 & 100 & 100 & 31300 \\
\hline $\begin{array}{l}2 \text { rodovias estaduais não } \\
\text { pavimentadas }\end{array}$ & $\begin{array}{l}2 \text { Distância mínima de } \\
50 \text { metros (buffer) }\end{array}$ & $\begin{array}{c}\text { Linear } \\
\text { decrescente }\end{array}$ & 50 & 50 & 50 & 29600 \\
\hline 3 caminhos e trilhas & $\begin{array}{l}3 \text { Distância mínima de } \\
30 \text { metros (buffer) }\end{array}$ & $\begin{array}{c}\text { Linear } \\
\text { decrescente }\end{array}$ & 30 & 30 & 30 & 25500 \\
\hline Lagoas de Tratamento (ETE's) & $\begin{array}{l}\text { Distância mínima de } \\
30 \text { metros (buffer) }\end{array}$ & & & & & \\
\hline Área de Mineração & $\begin{array}{l}\text { Distância mínima de } \\
50 \text { metros (buffer) }\end{array}$ & Linear crescente & zero & 50 & 50 & 50 \\
\hline $\begin{array}{l}\text { Falhas e Fraturas } \\
1 \text { falhas e fraturas }\end{array}$ & $\begin{array}{l}\text { Distância mínima de } \\
50 \text { metros (buffer) }\end{array}$ & Linear crescente & zero & 200 & 200 & 200 \\
\hline 2 diques e tendência de foliação & & Linear crescente & zero & 50 & 50 & 50 \\
\hline Declividade & $\begin{array}{l}\text { Declividade entre } 0 \text { e } \\
1 \% \text { e maior que } 30 \%\end{array}$ & $\begin{array}{l}\text { Definida pelo } \\
\text { usuário }\end{array}$ & \multicolumn{4}{|c|}{$\begin{array}{l}255 \text { para declividades entre } 1 \% \text { e } 10 \% \text {, } \\
240 \text { para declividades entre } 10 \% \text { e } 20 \% \\
230 \text { para declividades entre } 20 \% \text { e } 30 \%\end{array}$} \\
\hline Cobertura vegetal & - & $\begin{array}{l}\text { Definida pelo } \\
\text { usuário }\end{array}$ & \multicolumn{4}{|c|}{$\begin{array}{c}30 \text { para formações florestais, } 150 \text { para } \\
\text { agricultura, } 210 \text { para pastagem e } 255 \\
\text { para solo exposto }\end{array}$} \\
\hline Fragilidade & - & $\begin{array}{l}\text { Definida pelo } \\
\text { usuário }\end{array}$ & \multicolumn{4}{|c|}{$\begin{array}{l}250 \text { muito baixa, } 200 \text { baixa, } 150 \text { média, } \\
50 \text { alta, } \\
10 \text { muito alta }\end{array}$} \\
\hline Geologia & - & $\begin{array}{l}\text { Definida pelo } \\
\text { usuário }\end{array}$ & \multicolumn{4}{|c|}{ Ver Tabela 2} \\
\hline Solos & - & $\begin{array}{l}\text { Definida pelo } \\
\text { usuário }\end{array}$ & \multicolumn{4}{|c|}{ Ver Tabela 3} \\
\hline Bacias de Captação das ETA’s & - & $\begin{array}{l}\text { Definida pelo } \\
\text { usuário }\end{array}$ & \multicolumn{4}{|c|}{$\begin{array}{c}200 \text { para as bacias de captação e } 255 \text { fora } \\
\text { dessas bacias }\end{array}$} \\
\hline Limite da Área & Limite & - & \multicolumn{4}{|c|}{-} \\
\hline Municípios Vizinhos & $\begin{array}{c}\text { Áreas dos municípios } \\
\text { vizinhos dentro da área } \\
\text { de estudo }\end{array}$ & - & \multicolumn{4}{|c|}{-} \\
\hline
\end{tabular}


A Tabela 2 apresenta as unidades geológicas e os valores de adequabilidade atribuídos a elas e a Tabela 3 mostra as classes de solos e os respectivos valores atribuídos a eles.

A valoração dos fatores foi obtida da matriz de comparação par-a-par (processo hierárquico analítico). Esse algoritmo compara pares de fatores em termos de sua importância relativa e, depois de todas as combinaçóes possíveis, calcula um conjunto de pesos e uma razão de consistência. A ponderação obtida está na Tabela 4.

Os fatores foram agregados, numa primeira etapa, usando o procedimento da Combinação Linear Ponderada. Nesse método cada fator padronizado é multiplicado pelo seu peso correspondente, somados, e a soma é dividida pelo número de fatores. Obtém-se um cenário com risco médio e compensação máxima entre os fatores.

Numa segunda etapa, os fatores e as restrições foram agregados pelo processo da Média Ponderada Ordenada, no qual se aplica-se um segundo conjunto de pesos. Esse processo permite o estabelecimento de cenários com variação da compensação entre os fatores e do risco na análise. Foram identificados cinco cenários, buscando-se sempre explorar, ao máximo, a compensação entre os fatores. A Tabela 5 apresenta os cenários e respectivos valores de risco e compensação.

A atitude de risco, da análise, e o grau de compensação entre os fatores foram medidos, respectivamente, pelas
Tabela 2 - Adequabilidade das unidades geológicas

\begin{tabular}{|c|c|c|}
\hline Unidades & Descrição & Adequabilidade \\
\hline AcM & Complexo Cristalino & 255 \\
\hline AcX & Complexo Costeiro & 255 \\
\hline$€ O \gamma g$ & Fácies Granofirítica & 255 \\
\hline EO $\gamma \mathrm{a}$ & Fácies Graciosa & 255 \\
\hline $\mathrm{Ka} 1 \mathrm{~b}$ & Corpo Alcalino de Jacupiranga & 255 \\
\hline$P S \gamma_{c}$ & Fácies Cantareira & 255 \\
\hline PltM & Complexo Turvo Cajatí & 255 \\
\hline PltQ & Complexo Turvo Cajatí & 200 \\
\hline PltX & Complexo Turvo Cajatí & 150 \\
\hline Pltc & Complexo Turvo Cajatí & 100 \\
\hline Pltg & Complexo Turvo Cajatí & 255 \\
\hline $\mathrm{Qa}$ & Sedimentos Aluvionares & Zero \\
\hline Qc & Formação Cananéia & Zero \\
\hline Qi & $\begin{array}{l}\text { Sedimentos Cananéia } \\
\text { Indiferenciados }\end{array}$ & Zero \\
\hline Qm & Sedimentos Marinhos e Mistos & Zero \\
\hline Qp & Formação Pariqüera-Açu & Zero \\
\hline
\end{tabular}

Tabela 3 - Adequabilidade dos solos

\begin{tabular}{ccc}
\hline Classes & Descrição & Adequabilidade \\
\hline CXbd1 & Cambissolo & 50 \\
CXbd2 & Cambissolo & 50 \\
GXbd1 & Gleissolo & 0 \\
GXbd2 & Gleissolo & 0 \\
LVAd1 & Latossolo Vermelho & 255 \\
LVAd2 & Amarelo & 255 \\
Latossolo Vermelho & \\
PVAd & Amarelo & 200 \\
RLd & Chernossolo & 100 \\
\hline
\end{tabular}

Tabela 4 - Pesos obtidos da comparação par-a-par

\begin{tabular}{cccc}
\hline Fatores & Peso & Fatores & Peso \\
\hline Hidrografia 1(rio principal e afluentes principais) & 0.1224 & Fragilidade & 0.0424 \\
Hidrografia 2 (afluentes secundários) & 0.0456 & Sistema Viário 3 & 0.0187 \\
Áreas Alagadas & 0.1224 & Geologia & 0.0424 \\
Declividade & 0.1224 & Solos & 0.0424 \\
Cobertura Vegetal & 0.1224 & Falha 1 & 0.0424 \\
Áreas Urbanizadas & 0.0723 & Falha 2 & 0.0181 \\
Sistema Viário 1 & 0.1224 & Bacias de Captação & 0.0181 \\
Sistema Viário 2 & 0.0456 & & \\
\hline
\end{tabular}


variáveis RISCO (R) e COMPENSAÇÃO (C) dadas pelas Equações 1 e 2.

RISCO $=\frac{1}{n-1} x ! \eta_{n}-i \mathrm{xO}_{\mathrm{i}} \mathrm{A}$

COMPENSAÇÃO $=1-\sqrt{\frac{n x \sum_{i}\left(O_{i}-\frac{1}{n}\right)^{2}}{n-1}}$

onde,

- n é o número total de fatores;

- i é a ordem do fator;

- O é o peso para o fator de ordem i.

Calculou-se, a partir da projeção da população para um período de quinze anos (dados do IBGE), o volume de lixo produzido e a área necessária para sua disposição, para cada município (nesse período). O cálculo considerou as características de aterro celular descrito por Pereira Neto (1999). Obteve-se para o município de Jacupiranga, uma área de 3 ha; para o município Cajati, uma área de 12 ha; e para o município de Pariqüera-Açu uma área, de 6 ha.

Com os critérios apresentados na Tabela 1 e os cenários da Tabela 5 obtiveram-se cinco imagens finais. Essas imagens foram trabalhadas, individualmente, para cada um dos municípios, uma vez que as áreas necessárias eram diferentes. Para refinar a análise utilizou-se um critério pós-agregação fixando um valor para a adequabilidade mínima (sempre a maior possível) e para a área.

Para cada cenário da Tabela 5 obteve-se cinco imagens com adequabilidade mínima de 230 e área mínima de 3 ha para Jacupiranga; cinco imagens com adequabilidade mínima de 230 e área mínima de 12 ha para Cajati; e cinco imagens com adequabilidade mínima de 230 e área mínima de 6 ha para Pariqüera-Açu.

Pensou-se então em refinar um pouco mais a análise identificando a área mais próxima da área urbana com o algoritmo do caminho mínimo (pathway). Como superfície de atrito utilizou-se o sistema viário existente com o valor base de 1 . A ferrovia recebeu um valor muito alto (1000) porque o transporte dos resíduos não será feito por meio ferroviário. Os caminhos e trilhas receberam valor de (100) porque precisariam de manutenção para serem utilizadas com esta finalidade.
Tabela 5 - Cenários para análise

\begin{tabular}{ccc}
\hline Cenários & Risco & Compensação \\
\hline 1 & 0.50 & 1.00 \\
2 & 0.41 & 0.91 \\
3 & 0.37 & 0.87 \\
4 & 0.34 & 0.85 \\
5 & 0.38 & 0.88 \\
\hline
\end{tabular}

\section{RESULTADOS E DISCUSSÃO}

As Figuras 4, 5 e 6 apresentam os cenários obtidos para cada município.

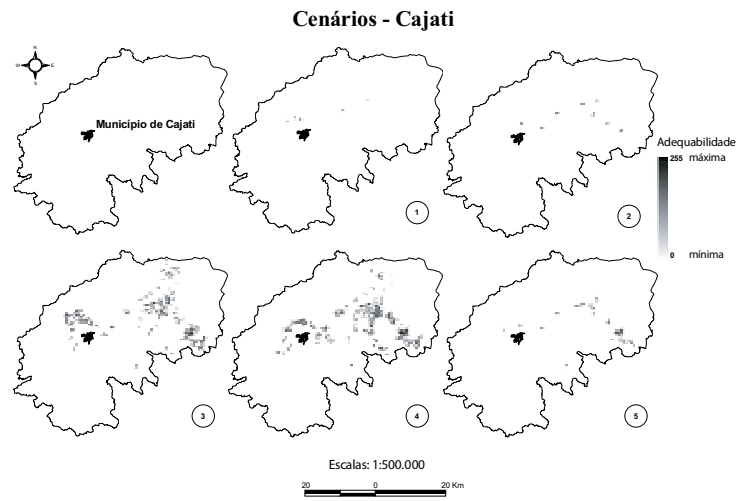

Figura 4 - Cenários para o município de Cajati
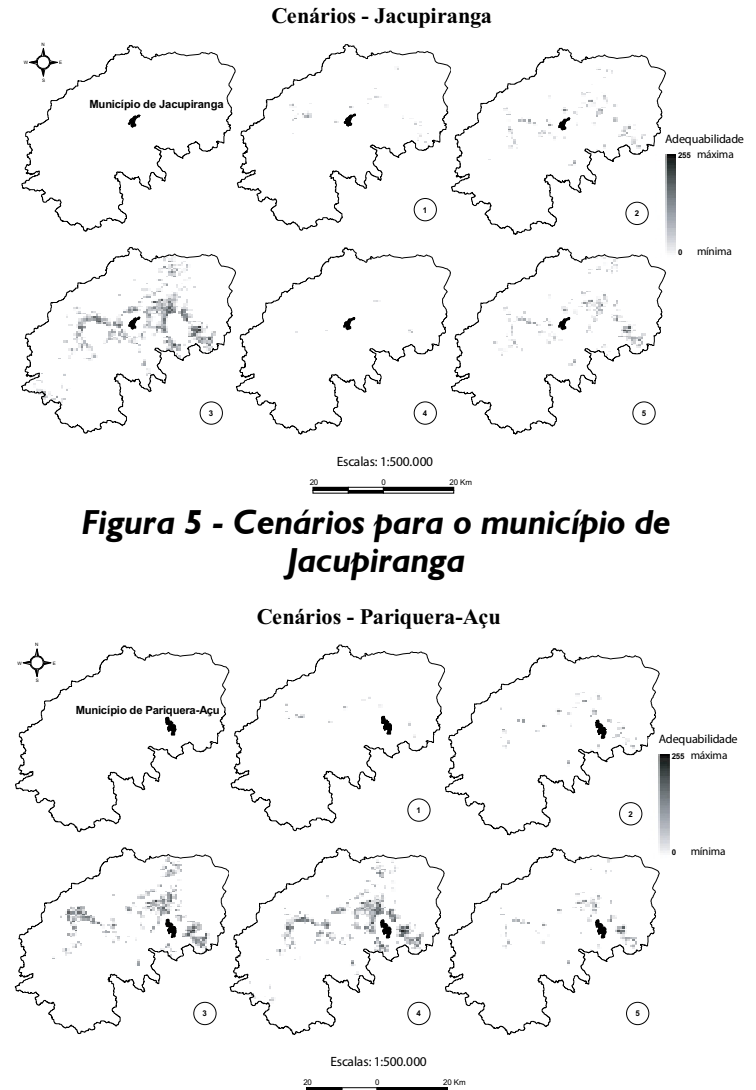

Figura 6 - Cenários para o município de Pariqüera-Açu 
A Tabela 6 mostra para cada cenário os menores percursos, em quilômetros, da área urbana (de cada um dos municípios) até uma das áreas, anteriormente, selecionadas como melhores.

Para o município de Cajati, que requer uma área de 12 ha para a disposição de seus rejeitos, um maior número de áreas foi encontrado para os cenários 3 e 4 . Entretanto, em termos do menor percurso da área urbana até uma das áreas selecionadas, resultados próximos foram obtidos para os cenários 3, 4 e 5 . Embora a diferença seja muito pequena, o cenário 5 seria o escolhido por apresentar o menor percurso e a maior compensação. O cenário 1 apresentou o pior resultado com aumento no percurso de quase $55 \%$ em relação ao escolhido.

O município de Jacupiranga, que requer uma área de 3 ha, obteve um maior número de áreas para a disposição de seus resíduos na simulação dos cenários 3 e 5 . Quanto ao menor percurso, da área urbana até uma das áreas selecionadas, resultados idênticos foram obtidos nos cenários 2 e 3 . O resultado do cenário 5 , embora não tenha sido o menor, ficou muito próximo dele. Para esse município optarse-ia, como melhor, pelo cenário 2, por envolver uma maior compensação entre os fatores. O cenário 1 apresentou um aumento no percurso de mais de $200 \%$ em relação ao 2 .

Os cenários 3 e 4 apresentaram um maior número de áreas para o município de Pariqüera-Açu. Percursos idênticos, e os menores foram obtidos com os cenários 3 e 4 , apesar do 2 apresentar valor próximo. O cenário 3 seria o mais indicado para uma primeira seleção, por envolver maior compensação e menor risco. Uma vez mais, o cenário 1 teve o pior desempenho, com aumento no percurso de mais de $250 \%$ em relação ao 3 .

As soluções encontradas estão dentro da distância mínima recomendada para viagem de ida e volta, que é de 30.000 metros (Melo, 2001).

As Figuras 7, 8 e 9 apresentam as melhores alternativas encontradas para os municípios de Cajati, Jacupiranga e Pariqüera-Açu.

$\mathrm{Na}$ realidade, aumentar o risco da análise implica em maturidade do usuário e bom conhecimento da área de estudo. Deve-se, também, sempre que possível, optar-se por um maior
Tabela 6 - Caminho mínimo $(\mathrm{Km})$ da área urbana até uma das melhores áreas

\begin{tabular}{cccc}
\hline Cenários & Jacupiranga & Cajati & Pariqüera-Açu \\
\hline C1 & 4,60 & 4,79 & 6,06 \\
C2 & 2,76 & 3,90 & 2,44 \\
C3 & 2,76 & 3,10 & 2,39 \\
C4 & 2,92 & 3,14 & 2,39 \\
C5 & 3,99 & 3,07 & 3,14 \\
\hline
\end{tabular}

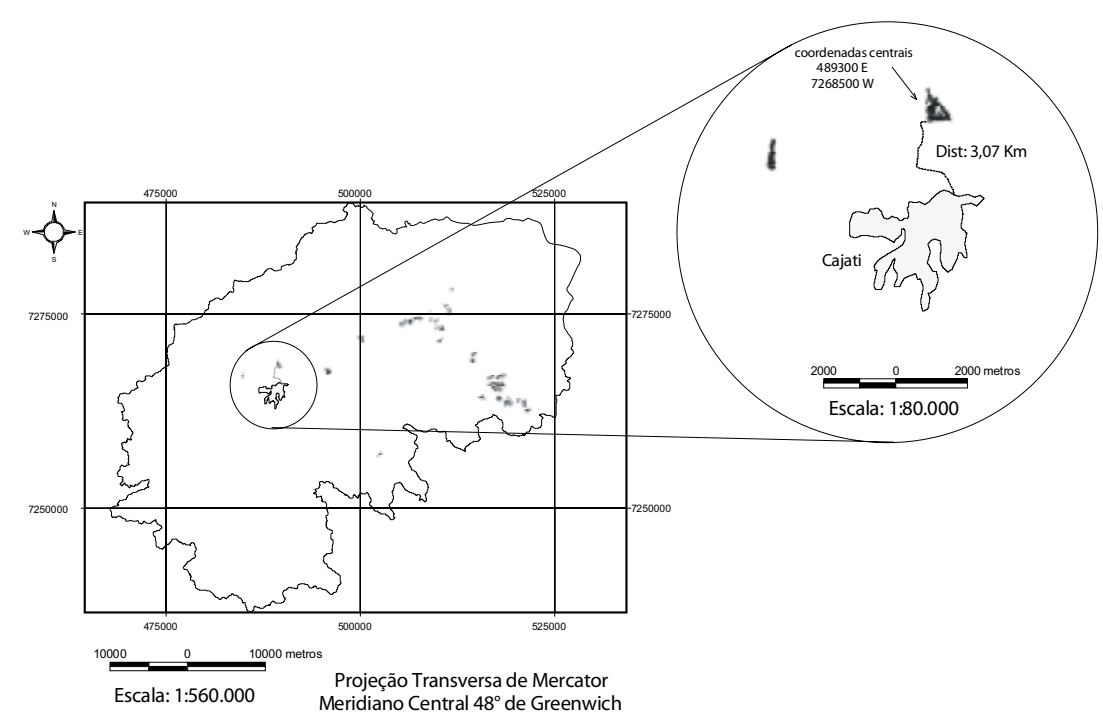

Figura 7 - Proposta identificada como a melhor para Cajati

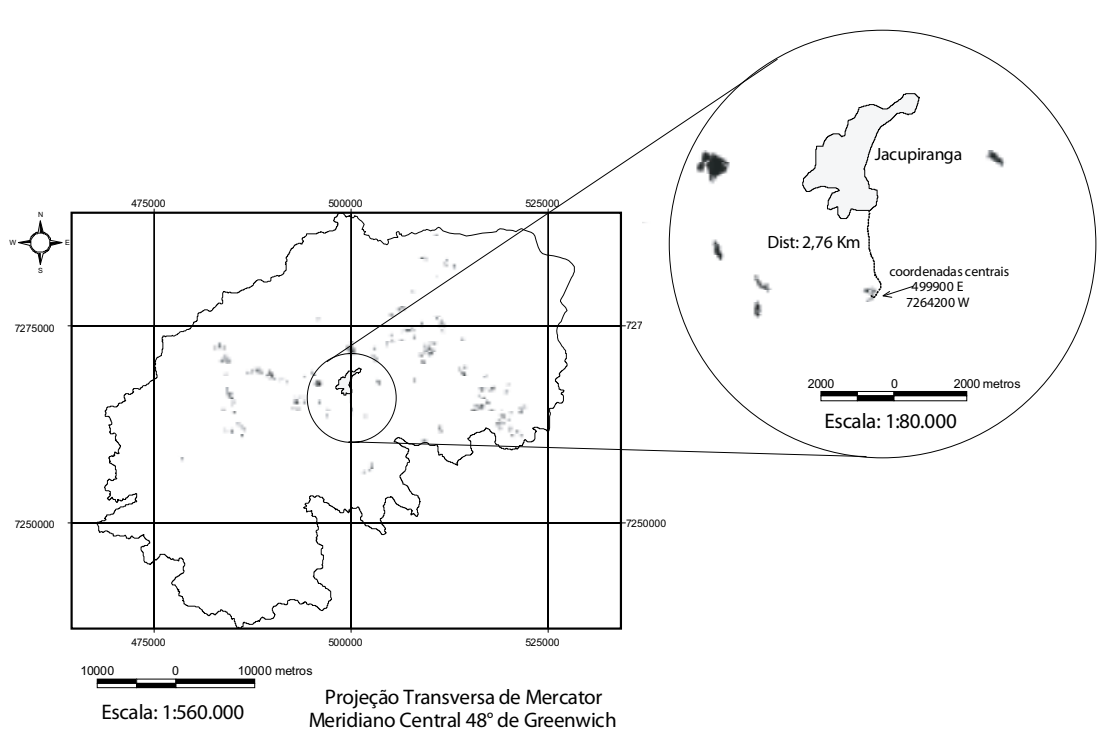

Figura 8 - Proposta identificada como a melhor para Jacupiranga 


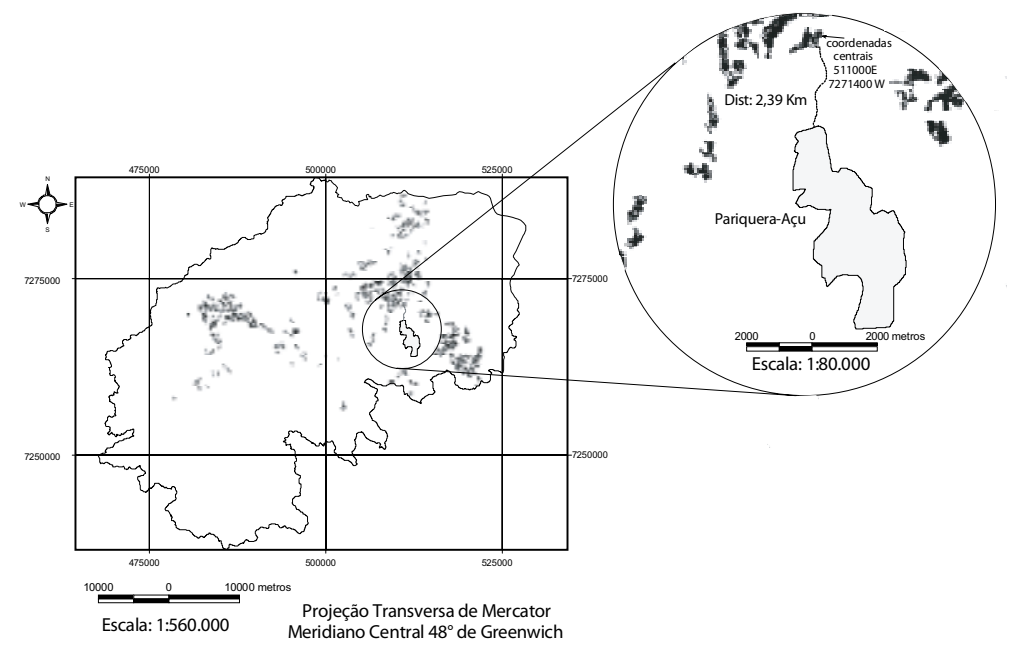

9 - Proposta identificada como a melhor para Pariqüera-Açu
Endereço para correspondência:

Maria Lúcia Calijuri

Departamento de Engenharia

Civil

Universidade Federal de Viçosa

Av. P. H. Rolfs, s/n. Viçosa - MG CEP 36570-000 Viçosa - MG -

Brasil

Tel.: (3I) 3899-3093

Fax (3I) 3899-2830

E-mail: calijuri@ufv.br detalhamento, que, em outras palavras, significa utilizar escalas maiores.

Análises realizadas com altos níveis de risco levam a resultados com grande número de áreas e altos valores de adequabilidade. Isto porque, fatores e ou locais com baixos valores de adequabilidade são ignorados e substituídos por aqueles que possuem os maiores valores.

\section{CONCLUSÕES}

A metodologia de análise multicritério mostrou-se adequada à seleção preliminar de locais para a disposição final de resíduos sólidos. Embora muitos cenários pudessem ser simulados, os cinco aqui definidos apresentaram resultados satisfatórios e coerentes com a realidade. A dificuldades para o uso desse processo é a estruturação da base de dados digital. Uma vez disponível, uma grande quantidade de cenários podem ser simulados de forma a atender os critérios do projeto.

Mapas em escalas maiores se existissem, deveriam ser utilizados para proporcionar análises mais detalhadas e refinadas. Da mesma forma, muitas outras informações, se existentes, e ou estivessem disponibilizadas, poderiam ser agregadas, proporcionando resultados mais robustos e de maior confiabilidade ao tomador de decisão.

A realidade do Brasil, entretanto, é outra e, ao que tudo indica, vai demorar muito tempo para mudar. Praticamente inexistem bases de dados digitais e, das raríssimas existentes, as escalas são muito pequenas. Quando não se tem quase nada, qualquer esforço realizado com ética, competência e responsabilidade, ajuda e muito. Não se pode esperar que condições ideais sejam reunidas para começar-se a agir.

\section{AGRADECIMENTOS}

Os autores agradecem à Capes e ao $\mathrm{CNPq}$ pelas bolsas concedidas.

\section{REFERÊNCIAS}

IAC - INSTITUTO AGRONÔMICO DE CAMPINAS. Mapa de Solos do Estado de São Paulo. 1999.

ISA - INSTITUTO SOCIOAMBIENTAL "Diagnóstico Socioambiental do Vale do Ribeira: Documento Sintese”. São Paulo. 1998.

KARMANN, I. Evolução e Dinâmica Atual do Sistema Cárstico do Alto Vale do Rio Ribeira de Iguape. Sudeste do Estado de São Paulo, São Paulo. Tese Doutorado. 1994.

MELO, A. L. O. Avaliação e selę̧ão de áreas para implantação de aterro sanitário utilizando lógica fuzzy e análise multi-critério: uma proposta metodológica. Aplicação ao Município de Cachoeiro de Itapemirim-ES. Viçosa: UFV, 246p. Dissertação Mestrado. 2001

PEREIRA NETO. Quanto vale nosso lixo. Viçosa-MG. Projeto Verde Vale - IEF/UNICEF, 70p. 1999.

SICCT - SECRETARIA DA INDÚSTRIA, COMÉRCIO, CIÊNCIA E TECNOLOGIA DO ESTADO DE SÃO PAULO. Mapa Geológico do Estado de São Paulo. Governo do Estado de São Paulo. Vol. II. 1981.

TSUHAKO, E. M. Seleção Preliminar de Locais Potenciais à Implantação de Aterro Sanitário na Sub-Bacia de Itupararanga (Bacia do Rio Sorocaba e Médio Tietê). Mestrado (Dissertação). Escola de Engenharia de São Carlos. Universidade de São Paulo. São Carlos, SP, 171p. 2004. 